\title{
Research on Allocation Method of Maintenance Material for Complex Mission
}

\author{
Yang Yingjie", Zhang Liu, Yu Yongli and Nie Chenglong \\ Department of Equipment Command and Management, Shijiazhuang Mechanical Engineering College, Shijiazhuang, \\ 050003, P.R. China
}

\begin{abstract}
From the analysis on the demand characteristic of maintenance material in wartime, take the maintenance material allocation of tactical single depot and multi-demand troops without supporting as the research object, according to describing the combat mission, put forward the real time allocation method of maintenance material for complex mission. Then, under the hypothesis that the material demand of ever demand troop is empirical distribution variables in ever phase mission, take the utility value of all maintenance material maximum as the optimization goal. The stochastic optimization model is built to get the material allocation up bound value of ever demand troop in ever phase mission. At last, use the relative model and algorithm given in this paper to an application example, the example shows the availability of the model built.
\end{abstract}

Keywords: Allocation, complex mission, maintenance material.

\section{INTRODUCTION}

The allocation of maintenance material is important part of equipment maintenance support in wartime. In the combat mission course, along with the continuance of mission, ever demand troop apply for the maintenance material to the depot continually, but the material depot may not get the support from the superior depot or other friendly troops for the enemy fire blockade, etc., so the depot usually cannot satisfy the material demand during the whole course of mission. In this case, the decision maker need determine the real time allocation method of material according to the material demand circs of ever combat troop to maximize the effect of existing maintenance material. So, in view of this practical problem, research the allocation method of maintenance material on the tactical single depot and multi-demand troops for the mission when resources shortage has important significance.

At present, the correlative research about the allocation of maintenance material is still little. According to the literature material accessed, existing research are all aiming at some time point, how to allocate the material in between the combat troops when the material resources is shortage. HE Peng, in literature [1], according to the combat troops' mission and the property, equipments' damage rate and the distribution, material inventory of ever level and other conditions, combining the maintenance material reserve mode in wartime, considering the difficult problem of the headquarters resources shortage, import the support degree with the weight as the allocation regulation one by one, based on these above, give the allocation flow, models and evaluation method of maintenance material in wartime. Then in literature [2], according to the reserve and support characteristic of maintenance material, give the allocation method of maintenance material in wartime which consider the mission, geographical environment, support time and other factors. Aiming at the difficult point about the support and supply of maintenance material is in base, give the method which can make the overall support effect optimal. But these researches above are all based on the hypothesis that the demand amount of maintenance material is doubtless. In literature [3], ZHANG Fangyu analyses the allocation's specific process of maintenance material, put forward that in the process of maintenance material allocation, implement to each according to his need when the sum of demand is less than the sum of depots, and implement the allocation which is based on the priority level of demand troops when the sum of demand is more than the sum of depots. But the distribution strategy is relatively rough. The allocation method of maintenance material for mission that this paper research is aiming at the time process, how to allocate the material in between the combat troops when the material resources is shortage.

\section{THE DESCRIPTION OF THE COMBAT MISSION}

Combat mission: The armed forces have to achieve some target and responsibility in order to meet the specific needs of the military [4].

Phase mission: The divided phase for the mission course according to the different of the mission used, ever phase mission has specific mission target.

Complex mission: It is combat course that the combat troop passes. It contains a series of phase missions during the whole mission course. 


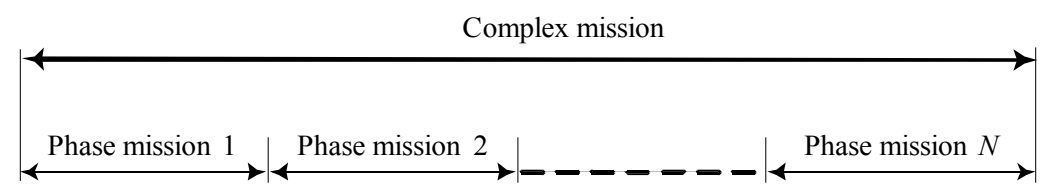

Fig. (1). An example. Complex mission.

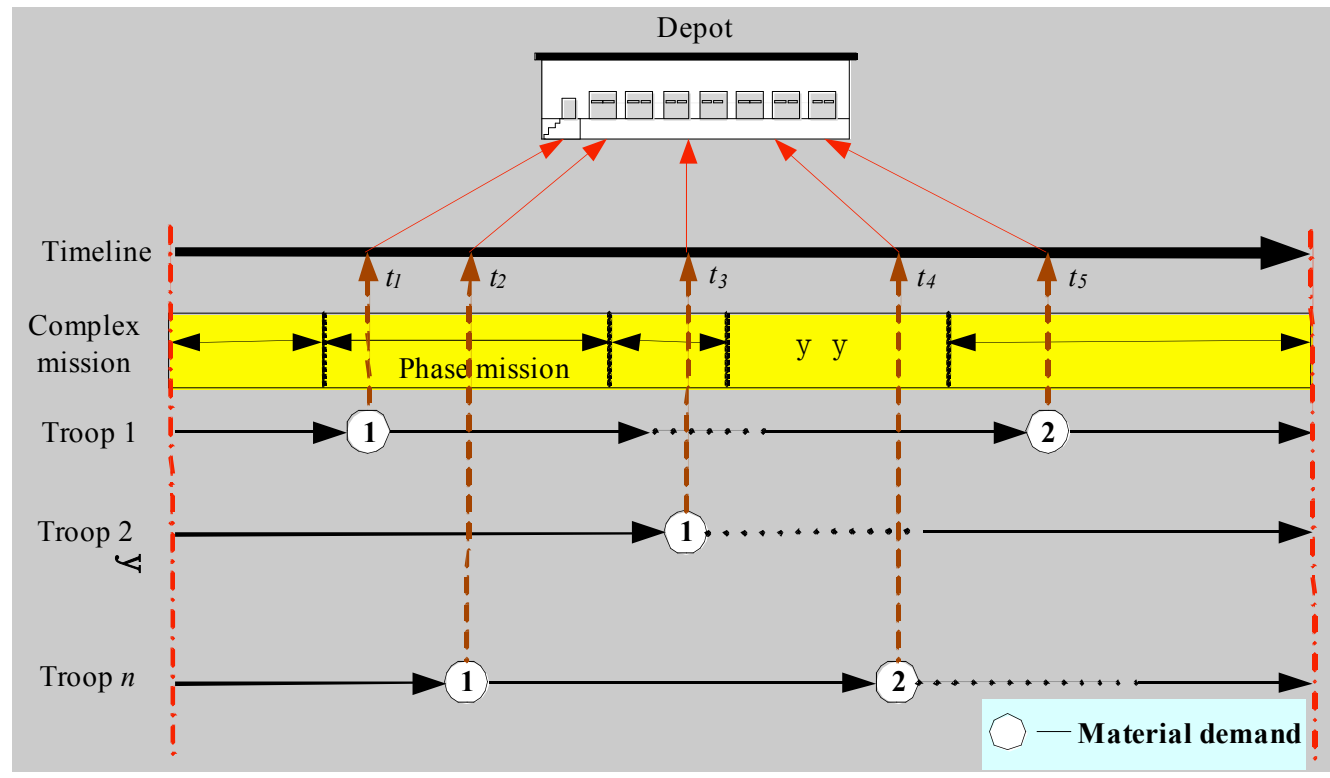

Fig. (2). The sketch map of maintenance material application during mission.

Take the tactical combat mission for instance, the whole tactical combat mission can be called complex mission, but the complex mission may not be the tactical combat mission. Because the discretional phase mission combination which is continuous in time can be called complex mission.

The tactical combat mission(complex mission) can be divided into several phase mission sequences that is continuous in time but not included each other when the mission is decompounded in time [5]. Show in Fig. (1).

\section{DEMAND CHARACTERISTIC ANALYSIS OF MAINTENANCE MATERIAL IN WARTIME}

In the course of mission, the sketch map of maintenance material demand application is show in Fig. (2). low.

From the Fig. (2), we can get the basic conclusions as be-

(1) The combat mission can be divided into several phase missions, in different phase mission, ever demand troop can produce maintenance material demand with many times according to the maintenance demands of damaged equipment. Because of the uncertainty of material consumption, the ever demand amount of material has the uncertainty.

(2) From the material depot to see the Fig. (1), there are demands of maintenance material produce constantly from ever combat troop during the mission. The demand time moment of ever combat troop has the uncertainty, and the demand number of ever combat troop also has the uncertainty.
So, in the course of mission, the demands of maintenance material produced by ever demand troop have two aspects of the uncertainty. One is the uncertain demand amount of maintenance material. Secondly, it is different that different demand troop apply for the material in time, and ever troop' demand number maybe exist many times. The allocation problem of maintenance material is to balance the two aspects of uncertainty reasonably to make all the maintenance material play to the greatest military benefits.

\section{THE DESCRIPTION OF ALLOCATION METHOD FOR COMPLEX MISSION}

According to the demand characteristic of maintenance material for complex mission, this paper give the up bound allocation value of material to demand troop $\mathrm{k}$ for phase mission i, satisfy $\sum x_{i}^{k}=Q, Q$ denote that the whole amount of some maintenance material in depot, show in Fig. (3), then in the phase mission i contained in complex mission, the decision maker determine whether to accept the demand troop's material application according to the up bound allocation value.

The detailed operating flow of maintenance material real time allocation method, show in Fig. (4).

If only the material application amount of demand troop $\mathrm{k}$ during phase mission $\mathrm{i}$ is less than the up bound allocation value $x_{i}^{k}$, allocate the corresponding material amount, if the application amount is more than the up bound allocation 


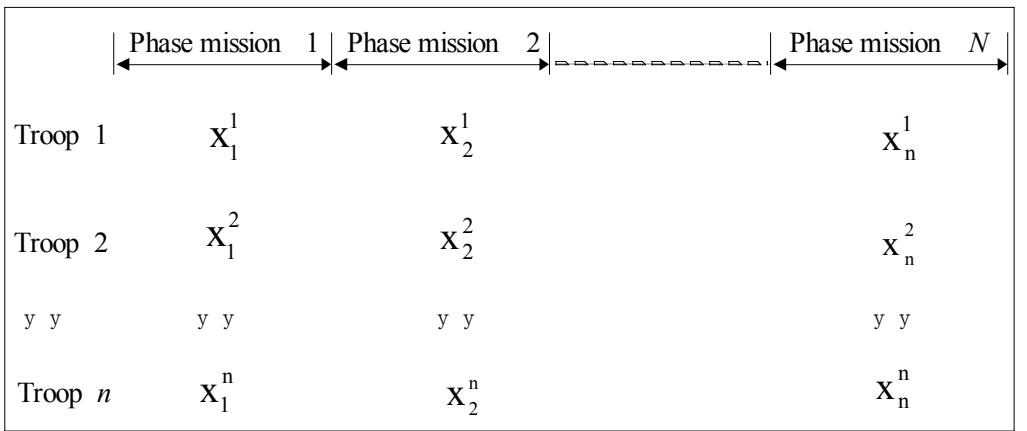

Fig. (3). The allocation sketch map.

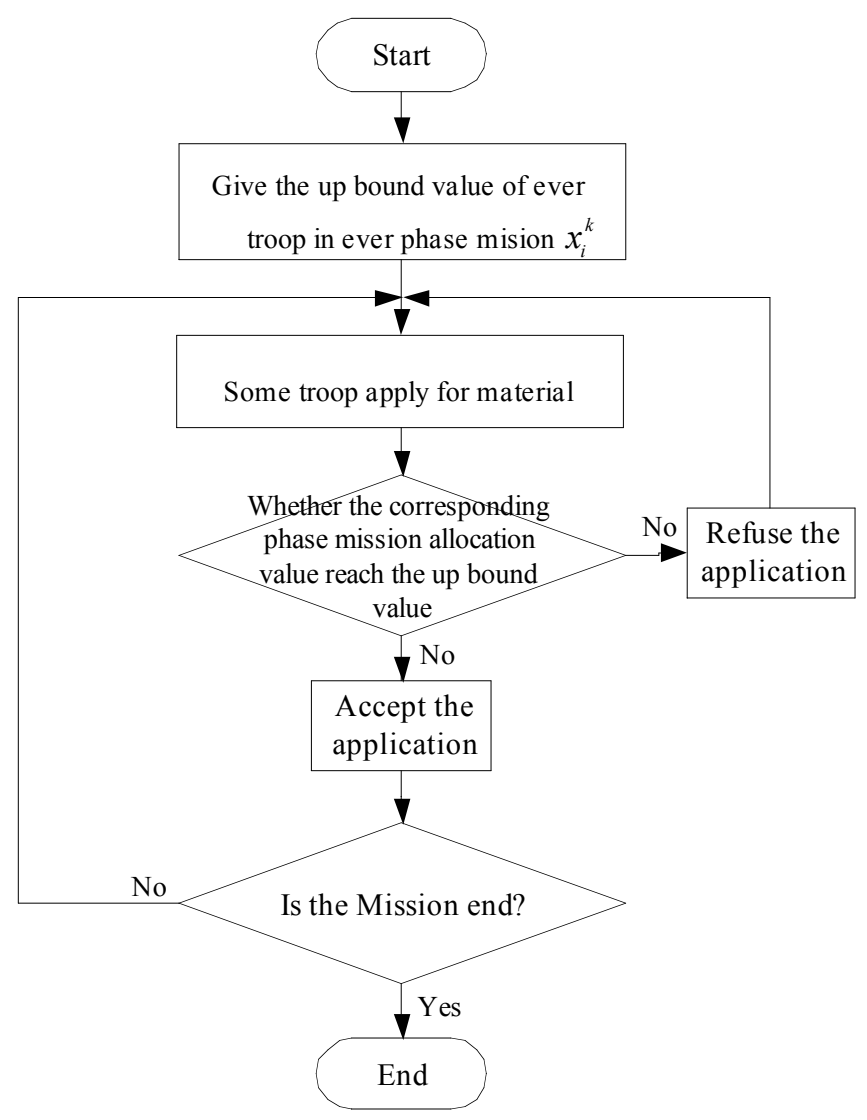

Fig. (4). The real time operating flow of material allocation method during phase mission.

value $x_{i}^{k}$, allocate a part of the demand amount as long as not exceed the $x_{i}^{k}$.

\section{MODEL BUILT}

Basic assumptions:

(1) Ever demand troop apply for material amount in ever phase mission is experience distribution variables.

(2) Only consider single variety material allocation, the sum of the material in depot is denoted by $Q$.

Assume some tactical mission is consist of $\mathrm{m}$ phase missions, there are $\mathrm{n}$ demand troops will produce the material application during ever phase mission. $x_{i}^{k}$ denote the up bound allocation value of material to the $\mathrm{k}$ demand troop in the i phase mission. $D_{i}^{k}$ denote the demand random variable of material for the $\mathrm{k}$ demand troop in the $\mathrm{i}$ phase mission.

This paper consider the optimization goal from the perspective of maintenance material, take the military benefit of all maintenance material maximum as the optimization goal. Firstly, give the definition as below.

Definition $p_{i}^{k}$ denote the utility of unit material for the $\mathrm{k}$ demand troop in the i phase mission, and $0 \leq p_{i} \leq 1$.

This value is correlative with the important degree of the demand troop, task priority and task urgent degree, etc. It can get from expert scoring method or comprehensive discussion hall technology. So this paper makes use of the utility value of all maintenance material maximum as the optimization goal of material allocation. The optimization function can be denoted as below.

$\max \sum_{i=1}^{m} \sum_{k=1}^{n} p_{i}^{k} \min \left\{D_{i}^{k}, x_{i}^{k}\right\}$

So far, the optimization model M1 can be built.

$\max \sum_{i=1}^{m} \sum_{k=1}^{n} p_{i}^{k} \min \left\{D_{i}^{k}, x_{i}^{k}\right\}$

s.t.

$\sum_{i=1}^{m} \sum_{k=1}^{n} x_{i}^{k}=Q$

$x_{i}^{k} \in Z^{+}$

\section{MODEL SOLUTION}

The model built above belongs to the optimization model with random variable. Because of the existence of random variable in model, the model cannot be direct solving. A classical solution method is to use the expectation of the random variable to replace the random variable for transform the model [6], but the shortcoming of this method cannot reflect the decision maker's risk attitude and preference, and 
it cannot ensure the feasibility of the result ever time. But this shortcoming can use the sensitive analysis to validate. However sensitive analysis is validation method ex post facto, the decision maker want to get the solution scheme beforehand, and the robust optimization is a kind of these methods.

According to the definition of Mulvey [7], the robust optimization is a method which combine the goal programming and scenario-based description for the random variable to solve the random programming, it can avoid the influence of the uncertainty and interference data to a certain extent and reflect the influence of the decision maker's risk attitude and preference to the goal function. The principle of robust optimization is balance the robust of solution and the robust of model. According to the robust optimization modeling ideas proposed in the literature [8], model M1 can be transformed to the form M2.

$$
\begin{gathered}
\max \sum_{s \in \Omega} \operatorname{Pr}_{s} \xi_{s}-\lambda \sum_{s \in \Omega} \operatorname{Pr}_{s}\left|\xi_{s}-\sum_{s \in \Omega} \operatorname{Pr}_{s} \xi_{s}\right| \\
-\sum_{s \in \Omega} \operatorname{Pr}_{s} \sum_{i \in m} \omega_{i}^{k} \sum_{k=1}^{n}\left|D_{i}^{k, s}-x_{i}^{k}\right|
\end{gathered}
$$

s.t.

$x_{i}^{k} \leq \max \left\{D_{i}^{k, s}\right\}, k=1,2, \ldots, n, s \in \Omega$

$\xi_{s}=\sum_{i=1}^{m} \sum_{k=1}^{n} p_{i}^{k, s} x_{i}^{k}, s \in \Omega$

$\sum_{s=1}^{S} \operatorname{Pr}_{s}=1$

$\sum_{i=1}^{m} \sum_{k=1}^{n} x_{i}^{k}=Q$

$x_{i}^{k} \in Z^{+}, \operatorname{Pr}_{s} \geq 0, s \in \Omega, i \in m, k=1,2, \ldots, n$

In the optimization model above, $s \in \Omega=\{1,2, \ldots, S\}$ denote a facultative scenario, Prs denote the probability of $\mathrm{s}$ coming true, this s can be considered as some possibility of demand variable, and Prs can be considered the probability of this possibility. In the actual circumstances, the value of $\mathrm{s}$ and Prs can get from the clustering analysis of experience data or the Bayesian updating method. In the optimization function (5), the first item denote the expectation of utility, the second item denote the average absolute deviation of utility, the third item denote the average absolute deviation of restriction disobeyed. The parameters $\lambda$ and $\omega_{i}^{k}$ are nonnegative weight parameter, among them, $\lambda$ can be considered the decision maker's risk coefficient, $\omega_{i}^{k}$ can be considered the castigatory weight of restriction disobeyed. The first and second items all can be considered the measure of result's robust, and the third item can be considered the measure of model's robust.
In order to got rid of the absolute value symbol in model M2 to use linear programming method to solve the model, $\mathrm{Li}$ [9] put forward a linear method to transform the absolute value item to the linear item, and give the transformation theorem.

Theorem consider the goal programming

$\min Z=|f(X)-g|$

s.t.

$X \in F$

It can be transformed to the form as below according to the linear method.

$\min \psi=f(X)-g+2 \delta$

s.t.

$g-f(X)-\delta \leq 0$

$\delta \geq 0$

$X \in F$

So model M2 can be transformed to the optimization model as below.

$$
\begin{gathered}
\max \sum_{s \in \Omega} \operatorname{Pr}_{s} \xi_{s}-\lambda \sum_{s \in \Omega} \operatorname{Pr}_{s}\left[\xi_{s}-\sum_{s \in \Omega} \operatorname{Pr}_{s} \xi_{s}+2 \delta^{s}\right] \\
-\sum_{s \in \Omega} \operatorname{Pr}_{s} \sum_{i=1}^{m} \sum_{k=1}^{n} \omega_{i}^{k}\left[D_{i}^{k, s}-x_{i}^{k}+2 \delta_{i}^{k, s}\right]
\end{gathered}
$$

s.t.

$\xi_{s}-\sum_{s \in \Omega} \operatorname{Pr}_{s} \xi_{s}+\delta^{s} \geq 0$

$D_{i}^{k, s}-x_{i}^{k}+\delta_{i}^{k, s} \geq 0$

$x_{i}^{k} \leq \max \left\{D_{i}^{k, s}\right\}, k=1,2, \ldots, n, s \in \Omega$

$\xi_{s}=\sum_{i=1}^{m} \sum_{k=1}^{n} p_{i}^{k, s} x_{i}^{k}, s \in \Omega$

$\sum_{s=1}^{S} \operatorname{Pr}_{s}=1$

$\sum_{i=1}^{m} \sum_{k=1}^{n} x_{i}^{k}=Q$

$x_{i}^{k} \in Z^{+}, \operatorname{Pr}_{s} \geq 0, \delta^{s} \geq 0, \delta_{i}^{k, s} \geq 0$

$s \in \Omega, i \in m, k=1,2, \ldots, n$

So far, the model $\mathrm{M}_{1}$ has been transformed to a classical linear programming model, use the programming software commonly used can, lingo for instance, solve it. 


\section{EXAMPLE}

Take the defensive fighting of some division as backdrop. Assume the division is consisted of 1 corps, 2 corps and 3 corps, it responsible for guarding some position. The combat mission of this division can be divided to three phase missions sequence, show in Fig. (5).

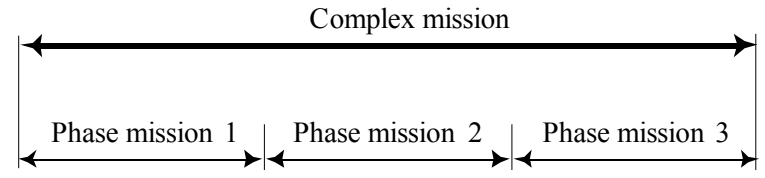

Fig. (5). Mission sketch map.

The division material depot may not get the support from the superior depot or other friendly troops for the enemy fire blockade, etc. The tactical depot stores some material 200 piece. The material demand possibility of the three corpses in ever phase mission can get in Table $\mathbf{1}$ according to the clustering analysis of experience data.
The utility of unit material for the three corpses in ever phase mission is shown in Table 2.

Because the parameter $\lambda$ can be considered the decision maker's risk coefficient, $\omega_{i}^{k}$ can be considered the castigatory weight of restriction disobeyed. When $\omega_{i}^{k}$ is fixed value, the $\lambda$ is smaller, the expectation of utility is bigger, and when $\lambda$ is fixed value, the expectation of utility as the growth of $\omega_{i}^{k}$ and diminishing. Here to take the parameters $\lambda=1, \omega_{i}^{k}=1$ for the model. Take the above data into the optimization model and use the linear programming software lingo to solve it, get the allocation scheme shown in Table 3 .

The example shows that the model given in this paper can give the feasible allocation scheme of maintenance material. Moreover, the solving of model depend on the parameters $\lambda$ and $\omega_{i}^{k}$, the values can use comprehensive discussion hall technology to get.

Table 1. The demand of material.

\begin{tabular}{|c|c|c|c|c|}
\hline & $\begin{array}{c}\text { Demand Possibility } \\
\text { (Probability) }\end{array}$ & $\begin{array}{c}\text { Phase mission } \\
1\end{array}$ & $\begin{array}{c}\text { Phase mission } \\
2\end{array}$ & $\begin{array}{c}\text { Phase mission } \\
3\end{array}$ \\
\hline \multirow{3}{*}{1 corps } & $1(0.5)$ & 25 & 32 & 19 \\
\hline & $2(0.3)$ & 22 & 30 & 14 \\
\hline & $3(0.2)$ & 30 & 35 & 23 \\
\hline \multirow{3}{*}{2 corps } & $1(0.5)$ & 33 & 19 & 42 \\
\hline & $2(0.3)$ & 27 & 14 & 37 \\
\hline & $3(0.2)$ & 38 & 23 & 43 \\
\hline \multirow{3}{*}{3 corps } & $1(0.5)$ & 40 & 20 & 26 \\
\hline & $2(0.3)$ & 35 & 16 & 22 \\
\hline & $3(0.2)$ & 42 & 25 & 30 \\
\hline
\end{tabular}

Table 2. The utility of unit material.

\begin{tabular}{|c|c|c|c|}
\hline & Phase mission & Phase mission & Phase mission \\
$\mathbf{2}$ & $\mathbf{1}$ & 0.6 & 0.9 \\
\hline \hline 1 corps & 1 & 1 & 0.7 \\
\hline 2 corps & 0.8 & 0.8 & 1 \\
\hline 3 corps & 0.7 & 0.8 \\
\hline
\end{tabular}

Table 3. The optimization allocation scheme of material.

\begin{tabular}{|l|c|c|c|}
\hline & Phase Mission 1 & Phase Mission 2 & Phase Mission 3 \\
\hline \hline 1 corps & 22 & 13 & 14 \\
\hline 2 corps & 27 & 14 & 37 \\
\hline 3 corps & 35 & 16 & 22 \\
\hline
\end{tabular}




\section{CONCLUSION}

The allocation of maintenance material is important part of tactical material supply support problem. This paper establishes the optimization model through to the introduction of combat mission to settle the material allocation problem for complex mission. Put forward a real time allocation method. The example analyze this model can give the accessorial decision for the material allocation in wartime. It has certain practical significance and military value.

\section{CONFLICT OF INTEREST}

The authors confirm that this article content has no conflict of interest.

\section{ACKNOWLEDGEMENTS}

This work was financially supported by the National Research Project Foundation (51319060104), and the Integrate logistics Support Team in the Maintenance Engineering Institute gave me a lot of research help. Specially, I wish to express my sincere appreciation to Prof. Zhang, it is under her guidance directly, this paper can be successfully accomplished.

\section{REFERENCES}

[1] H. Peng, Z. Fangyu, Y. Na, and W. Huang, "Distribution Strategy of Maintenance Material at Wartime", Journal of Ordnance Engineering College, vol. 17, pp. 46-49, 2005.

[2] H. Peng, G. Qi, Z. Fangyu, etc. "Study on Weapon Maintenance Material Allocation in Wartime", Journal of Projectiles, Rockets, Missiles and Guidance, vol. 25, pp. 606-611, 2005.

[3] Z. Fangyu, G. Qi, H. Peng, etc. "Research on Equipment Maintenance Material Distribution and Supply Method", Logistics SciTech, vol. 29, pp. 108-110, 2005.

[4] Military academy of Sciences, "Army Language of The Chinese People's Liberation Army”, CA: Beijing, Press: Military Science, pp. $64,2011$.

[5] C. Nie, "Research on ILS Models for Equipment Combat Unit", the Ph.D. Dissertation Shijiazhuang Mechanical Engineering College, 2005.

[6] K. T. Talluri, and G. Van Ryzin, "A randomized linaer programming method for computing network bid prices", Transportation Science, vol. 33, pp. 207-216, 1999.

[7] J. M. Mulvey, R. J. Vanderbei, and S. A Zenios, "Robust Optimization of Large-scale System", Operations Research, vol. 43, pp. 673-684, 1995 .

[8] C. S. Yu, and H. L. Li, "A Robust Optimization Model for Stochastic Logistics Problems", International Journal of Production Economics, vol. 64, pp. 85-397, 2000.

[9] H. L. Li, "An Efficient Method for Solving Linear Goal Programming Problems", Journal of Optimization Theory and Application, vol. 90, pp. 465-469, 1996.

Received: June 10, 2015

Revised: July 29, 2015

Accepted: August 15, 2015

(C) Yingjie et al.; Licensee Bentham Open.

This is an open access article licensed under the terms of the Creative Commons Attribution Non-Commercial License (http://creativecommons.org/licenses/by-nc/3.0/) which permits unrestricted, non-commercial use, distribution and reproduction in any medium, provided the work is properly cited. 